\title{
Ultrasensitive Micro String Resonators for Solid State Thermomechanical Analysis of Small and Large Molecules
}

Karl, Maximilian; Larsen, Peter E.; Rangacharya, Varadarajan P.; Hwu, En Te; Rantanen, Jukka; Boisen, Anja; Rades, Thomas

Published in:

Journal of the American Chemical Society

Link to article, DOI:

10.1021/jacs.8b09034

Publication date:

2018

Document Version

Peer reviewed version

Link back to DTU Orbit

Citation (APA):

Karl, M., Larsen, P. E., Rangacharya, V. P., Hwu, E. T., Rantanen, J., Boisen, A., \& Rades, T. (2018). Ultrasensitive Micro String Resonators for Solid State Thermomechanical Analysis of Small and Large Molecules. Journal of the American Chemical Society, 140(50), 17522-17531.

https://doi.org/10.1021/jacs.8b09034

\section{General rights}

Copyright and moral rights for the publications made accessible in the public portal are retained by the authors and/or other copyright owners and it is a condition of accessing publications that users recognise and abide by the legal requirements associated with these rights.

- Users may download and print one copy of any publication from the public portal for the purpose of private study or research.

- You may not further distribute the material or use it for any profit-making activity or commercial gain

- You may freely distribute the URL identifying the publication in the public portal 


\section{Article}

Subscriber access provided by DTU Library

\section{Ultra Sensitive Micro String Resonators for Solid State Thermomechanical Analysis of Small and Large Molecules}

Maximilian Karl, Peter Emil Larsen, Varadarajan Rangacharya, En Te Hwu, Jukka Rantanen, Anja Boisen, and Thomas Rades

J. Am. Chem. Soc., Just Accepted Manuscript • DOI: 10.1021/jacs.8b09034 • Publication Date (Web): 23 Nov 2018

Downloaded from http://pubs.acs.org on December 5, 2018

\section{Just Accepted}

"Just Accepted" manuscripts have been peer-reviewed and accepted for publication. They are posted online prior to technical editing, formatting for publication and author proofing. The American Chemical Society provides "Just Accepted" as a service to the research community to expedite the dissemination of scientific material as soon as possible after acceptance. "Just Accepted" manuscripts appear in full in PDF format accompanied by an HTML abstract. "Just Accepted" manuscripts have been fully peer reviewed, but should not be considered the official version of record. They are citable by the Digital Object Identifier (DOI@). "Just Accepted" is an optional service offered to authors. Therefore, the "Just Accepted" Web site may not include all articles that will be published in the journal. After a manuscript is technically edited and formatted, it will be removed from the "Just Accepted" Web site and published as an ASAP article. Note that technical editing may introduce minor changes to the manuscript text and/or graphics which could affect content, and all legal disclaimers and ethical guidelines that apply to the journal pertain. ACS cannot be held responsible for errors or consequences arising from the use of information contained in these "Just Accepted" manuscripts. 


\title{
Ultra Sensitive Micro String Resonators for Solid State Thermo- mechanical Analysis of Small and Large Molecules
}

\author{
Maximilian Karl ${ }^{\dagger \ddagger}$, Peter E. Larsen ${ }^{\ddagger}$, Varadarajan P. Rangacharya ${ }^{\ddagger}$, En Te Hwu ${ }^{\ddagger}$, Jukka \\ Rantanen $^{\dagger}$, Anja Boisen ${ }^{\ddagger ¥}$, and Thomas Rades ${ }^{{ }^{*}}$ \\ ${ }^{\dagger}$ University of Copenhagen, Department of Pharmacy, Universitetsparken 2, 210o Copenhagen, Denmark \\ ${ }^{\ddagger}$ Technical University of Denmark, Department of Micro- and Nanotechnology, Ørsteds Plads, 280o Kgs. Lyngby, \\ Denmark \\ ${ }^{*}$ Danish National Research Foundation and Villum Fondens Center for Intelligent Drug delivery and sensing Using \\ microcontainers and Nanomechanics (IDUN)
}

KEYWORDS. thermal analysis, MEMS, resonator, string, $\beta$-relaxation, glass transition

\begin{abstract}
Thermal analysis plays an important role in both industrial and fundamental research and is widely used to study thermal characteristics of a variety of materials. However, despite considerable effort using different techniques, research struggles to resolve the physico-chemical nature of many thermal transitions such as amorphous relaxations or structural changes in proteins. To overcome the limitations in sensitivity of conventional techniques and to gain new insight into the thermal and mechanical properties of small and large molecule samples, we have developed an instrumental analysis technique using resonating low stress silicon nitride microstrings. With a simple sample deposition method and post process data analysis, we are able to perform rapid thermal analysis of direct instrumental triplicate samples with only pico- to nanograms of material. Utilizing this method, we present the first measurement of amorphous alpha and beta relaxation, as well as liquid crystalline transitions and decomposition of small molecule samples deposited onto a micro string resonator. Furthermore, sensitive measurements of the glass transition of polymers and yet unresolved thermal responses of proteins below their apparent denaturation temperature, which seem to include the true solid state glass transition of pure protein, are reported. Where applicable, thermal events detected with the setup were in good agreement with conventional techniques such as differential scanning calorimetry and dynamic mechanical analysis. The sensitive detection of even subtle thermal transitions highlights further possibilities and applications of resonating microstrings in instrumental physico-chemical analysis.
\end{abstract}

\section{INTRODUCTION}

Thermal analysis comprises of an important analytical tool-box for the physico-chemical characterization of a variety of analytes across many fields of chemical sciences: for material and polymer scientists, first and second order phase transitions are crucial for material processability as well as for the application range of the final product. Pharmaceutical research, often focusing on small molecules or proteins as active ingredients, is particularly interested in transitions related to the chemical and physical stability of the formulation. A range of methods has been established to analyze these materials as they change with temperature, each with its own advantages and limitations. Here, we introduce an instrumental analysis technique using resonating silicon nitride $\left(\mathrm{Si}_{\mathrm{x}} \mathrm{N}_{\mathrm{y}}\right)$ microstring sensors to study the thermal and mechanical properties of small molecule drugs, polymers and proteins with only pico- to nanograms of sample.
Resonating Micro- and Nano Electro Mechanical Systems (MEMS, NEMS) of different geometries have been utilized for a variety of applications such as oscillators and filters, as well as chemical, mass and humidity sensors. ${ }^{1-5}$ However, research into probing thermal characteristics of samples deposited onto the sensors is still in its infancy with only a few proof-of-concept studies reported in the literature. ${ }^{6-14}$ All but one of these studies focus on polymers. Furthermore, the main limitations are the applied sample deposition methods: specialized spray- or spin coating, ink jet printing or melt infiltration are used to deposit the sample on the sensors. Spray coating and ink jet printing can only be applied to specific samples and their process optimization is tedious. ${ }^{15-16}$ Melt infiltration combined with a specific suspended microchannel geometry can only be used if the sample does not degrade upon heating or melting and if the sample possesses a sufficiently low melt viscosity. ${ }^{17}$ Importantly, all of these methods physically alter the sample. 
a)

3

4

5

6

7

8

9 b)

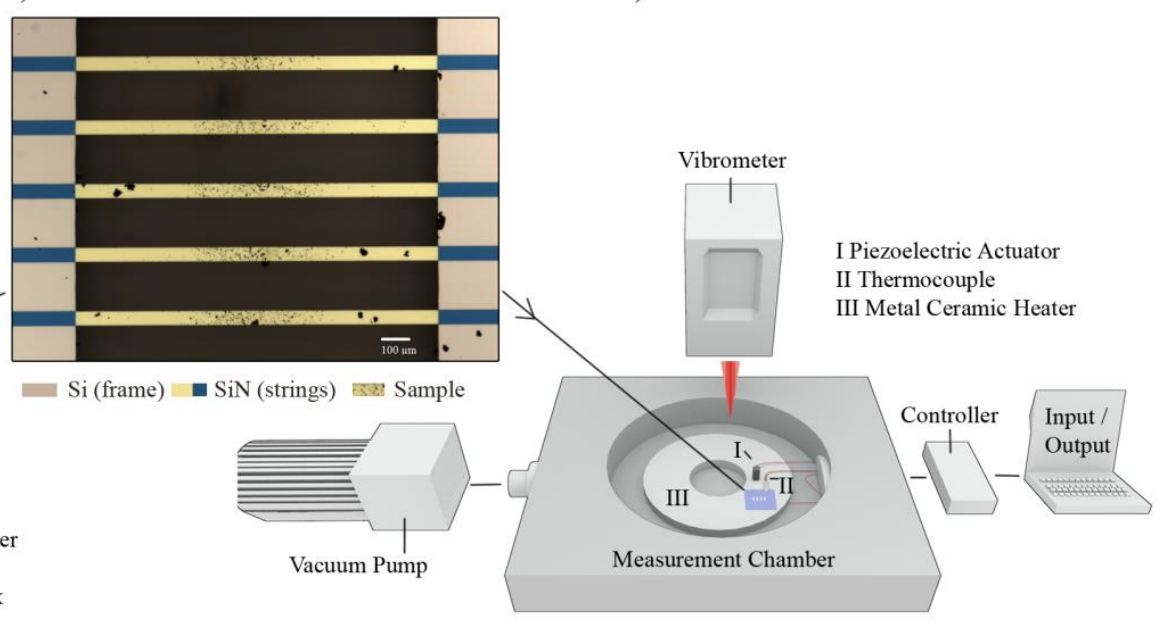

Figure 1. (a) Sampling chamber (b) Microstring chip sensor coated with amorphous carvedilol (c) Overview of the instrumental setup

The sampling technique used in this study is a direct solid state deposition method (Figure 1a). The sample is transferred onto a sieve, which is used for initial size reduction and placed above the sampling chamber. A vacuum is applied through a hole, drilled in the bottom part of the chamber. The resulting air flow forces the samples to deposit on the strings (Figure $1 \mathrm{~b}$ ) by inertial impaction. ${ }^{18}$ Furthermore, a shadow mask is used to define the sample location on the string sensor. After the sampling procedure, the sensor chip is transferred to a homemade temperature stage, placed in a vacuum chamber. A laserDoppler-vibrometer is used for readout of the string sensor and a controller sets and monitors the temperature profiles. An overview of the measurement setup is given in Figure 1c.

The measuring principle used in this work is based on tracking changes in the resonant behavior of the micro string sensors and relating them to changes in the analyzed sample. Every mechanical structure has a fundamental mechanical Eigenfrequency that is a function of its material properties and geometry. In real world structures where mechanical losses are present, these frequencies are called resonance frequencies. As seen by equation $1^{19}$, an increase in stiffness or tensile stress or a decrease in effective mass lead to higher resonance frequencies of string resonators.

$$
f_{\text {res }, n}=\frac{n}{2 l} \sqrt{\frac{\sigma}{\rho}}, n=1,2,3 . .
$$

$\mathrm{n}$ : resonance mode number, 1 : length of the string $\sigma$ : tensile stress, $\rho$ : mass density

Determining the quality factor $(\mathrm{Q})$, a measure of the dissipation of mechanical energy in the resonator system, reveals additional information about the viscous damping in the sample.

During the experiments, the entire microchip is heated. As the silicon frame expands more than the $\mathrm{Si}_{\mathrm{x}} \mathrm{N}_{\mathrm{y}}$ strings during heating, the strings' tensile stress increases, leading to higher resonance frequencies. Thermal transitions of samples deposited onto the string affect the physical properties of the system and result in frequency slope changes, as well as in changes of $\mathrm{Q}^{8}$

The method presented here is referred to as Micromechanical Thermal Analysis (MTA) and has many advantages compared to conventional techniques. It allows the use of very small sample sizes (o.1 to $345 \mathrm{ng}$ ), which is beneficial in settings where only small amounts of compounds are available, such as in pharmaceutical research and development. With the setup used in this study, heating rates of $40^{\circ} \mathrm{C} / \mathrm{min}$ can be achieved, while conventional techniques such as Modulated Temperature Differential Scanning Calorimetry (mDSC) and Dynamic Mechanical Analysis (DMA) are usually limited to heating rates of 0.5 $-5^{\circ} \mathrm{C} / \mathrm{min} .^{20-21}$

The measurement laser is able to jump between individual strings clamped onto the same chip. In this way, spectra for samples on every string can be recorded and $f_{r}$ and $\mathrm{Q}$ are extracted from the frequency response spectra after the measurement has finished. As sampling through inertial impaction is an inherently random process, each string supplies an independent measurement. In our study, three strings per microchip were measured and analyzed simultaneously, to create an instant instrumental triplicate. These advances drastically decrease the measurement time per sample.

Using this method, we hereby show the first measurements of both the alpha and the beta relaxation of amorphous small molecules, as well as liquid crystalline phase transitions probed with a micromechanical string resonator. These processes are of great interest in pharmaceutical research, as amorphous formulations are a promising approach to counteract the negative impact of low aqueous solubility on bioavailability. ${ }^{22}$ The use of amorphous formulations is however limited to their unstable nature, leading to only a few marketed products. ${ }^{23}$ The alpha re- 
laxation (or glass transition, $\mathrm{T}_{\mathrm{g}}$ ) has previously been described as an important indicator for amorphous stability. ${ }^{22}$ Moreover, recent focus of physico-chemical investigation of glassy materials is also including the beta relaxa$\operatorname{tion}^{24}\left(\mathrm{~T}_{\beta}\right)$, which is only accessible by more sensitive measuring techniques than mDSC, that require bulk sample sizes ( $>100 \mathrm{mg}$ ) such as Dielectric Spectroscopy ${ }^{25}$ and $\mathrm{DMA}^{21}$ or more advanced vibrational spectroscopic techniques such as Terahertz Spectroscopy. ${ }^{26}$

In this study, we also present sensitive measurements of the $T_{g}$ of polymers. Besides its importance for amorphous stability and processability, the $\mathrm{T}_{\mathrm{g}}$ is an important parameter for the application range of the polymer. For example, rubber elastomers are used above their $T_{g}$, whereas amorphous plastics are mostly used below their $\mathrm{T}_{\mathrm{g}}{ }^{27}$

The solid state sampling technique used in this study, also allows for the probing of protein samples. An important thermal transition of proteins with respect to stability as well as biological activity is the denaturation onset. Moreover, pharmaceutical research and technology, as well as the field of biomimetics are interested in thermal phenomena that happen below the denaturation temperature for reasons of stability, processability and biological activity. ${ }^{28-29}$ Therefore it is important to have sensitive tools to better characterize these samples. Consequently, this study includes the temperature profiles of two biologically active proteins as freeze dried samples showing several, yet unknown, thermal transitions up to their apparent denaturation onset.

All samples and their respective thermal transitions analyzed in this study are compared to conventional methods, namely mDSC, DMA and Thermogravimetric Analysis (TGA).

\section{EXPERIMENTAL SECTION}

\section{Quench Cooling}

Quench cooling was performed by heating the crystalline drug $10^{\circ} \mathrm{C}$ above its respective melting point in an aluminium pan for two minutes and quickly placing the pan on a metal block at room temperature afterwards. The resulting glass was gently ground in a mortar to obtain a homogeneous powder. Drug samples were confirmed to be amorphous by X-Ray Powder Diffraction (XRPD).

\section{XRPD}

XRPD measurements were recorded at room temperature using a PANalytical X'Pert PRO diffractometer (PW3040/60, Alemo, The Netherlands) equipped with a $\mathrm{Cu} \mathrm{K} \alpha$ anode $(1.54187 \mathrm{~A})$, voltage: $45 \mathrm{kV}$, current: $40 \mathrm{~mA}$ in the range of $4^{\circ}-34^{\circ} 2 \Theta$ with a scan speed of $0.067^{\circ} / \mathrm{s}$, using $99.45 \mathrm{~s} /$ step. The data was analysed using X'Pert HighScore Plus (Version 2.2d, Alemo, The Netherlands) and MatLab R2o17a.

\section{DMA}

DMA measurements were performed on a Q8oo Dynamic Mechanical Analyser with a liquid nitrogen cooling system (TA Instruments, New Castle, DE, USA). A powder clamp (instrument's operation mode: 'Dual Canteliver') was used to characterize the thermal transitions. The deformation amplitude was set to $20 \mu \mathrm{m}$ with a frequency of $1 \mathrm{~Hz}$. Temperature ramps were performed at $3^{\circ} \mathrm{C} / \mathrm{min}$ and beta relaxation values were determined with TRIOS software (version 4.1.1) by taking the respective peak maximum of the tan delta signal.

\section{DSC and $\mathrm{mDSC}$}

DSC thermograms were obtained using a Discovery DSC (TA Instruments, New Castle, DE, USA) with a nitrogen gas flow of $50 \mathrm{ml} / \mathrm{min}$. Samples of 3 to $8 \mathrm{mg}$ were crimped in an aluminium sample pan and heated at a rate of $10^{\circ} \mathrm{C} / \mathrm{min}$. To clearly identify the $\mathrm{Tg}$, polymer samples were also measured with $\mathrm{mDSC}$ (heating rate: $3^{\circ} \mathrm{C} / \mathrm{min}$ ). The modulation amplitude was set to $0.2120{ }^{\circ} \mathrm{C}$ with a period of $40 \mathrm{~s}$. Tg values were determined using TRIOS software (version 4.1.1). The $\mathrm{Tg}$ was taken at the midpoint of the change in heat capacity $(\Delta \mathrm{Cp})$. Crystallization and melting points were taken as the respective peak maximum.

\section{TGA}

TGA was performed on a Discovery TGA from TA Instruments with a heating rate of $10^{\circ} \mathrm{C} / \mathrm{min}$. Sample sizes were 4 to $11 \mathrm{mg}$ and decomposition onset values were determined using TRIOS software (version 4.1.1.) as tangent intersects.

\section{MTA - Instrumental Setup}

The heating stage consisted of a metal ceramic heater (HT19R, Thorlabs Inc, New Jersey, USA), used for heating the microchip and a Raspberry Pi 2 Model B (Raspberry Pi Foundation, United Kingdom), used to set and control the temperature, measured by a thermocouple (K-Type) in direct contact with the microchip. The setup was placed in a vacuum chamber to eliminate air damping of the micro resonators and thus reduce measurement noise. The change in frequency was measured with a laserDoppler-vibrometer (MSA-50o, Polytec GmbH, Germany). Furthermore, a piezoelectric element (NAC6o24, Noliac A/S, Kvistgaard, Denmark) was used for actuation. A serial configuration membrane (PJ 15347, Leybold GmbH, Germany) and turbo pump (HiPace 8o, Pfeiffer Vacuum $\mathrm{GmbH}$, Germany) created the high vacuum $\left(<10^{-5} \mathrm{mbar}\right)$. For particle size selection, a standard $32 \mu \mathrm{m}$ sieve analysis sieve (Haver \& Boecker oHG, Germany) was used. The shadow mask for focusing the sample deposition in the center of the string was made by mechanically destroying the strings of a regular fabricated string sensor.

\section{MTA - String Sensor Fabrication}

SiN microstring sensors were cleanroom fabricated by using Low Pressure Chemical Vapour Deposition to deposite silicon rich silicon nitride $\left(\mathrm{Si}_{\mathrm{x}} \mathrm{N}_{\mathrm{y}}\right)$ on a silicon wafer (4", DSP, $350 \mu \mathrm{m})$. Microstrings are defined through standard UV lithography and dry etching. The same steps were used on the backside to enable device release through a $\mathrm{KOH}$ etch. To facilitate easy sampling, strings with 100 and $200 \mathrm{~nm}$ in thickness, 30 and $50 \mu \mathrm{m}$ in width and 1000 or $1500 \mu \mathrm{m}$ in length were used in this study. 


\section{MTA - Data Analysis}

Data analysis of the MTA measurements was performed in MatLab R2017a. Tracking of the resonance peaks from every raw data spectrum was done by using either the build in findpeaks function or a probabilistic model with Gaussian process priors. To compare and ensure correct tracking, every measurement shown in this study was also tracked manually by selecting a frequency range around the resonance peak of every spectra and identifying the maximum frequency in the given range. Tracked frequency values were interpolated against the temperature (as recorded by the Raspberry $\mathrm{Pi}$ ) over the measurement time. The $\mathrm{Q}$ factor was estimated by fitting an arctangent function (see supporting information) to the phase signal of the frequency response spectrum. Because measuring $\mathrm{Q}$ is inherently prone to noise, moving average or Savitzky Golay filters were applied to the $Q$ signal. A comparison between raw and filtered data for the $Q$ (example: amorphous cimetidine) is supplied in the supporting information.

\section{RESULTS AND DISCUSSION}

\section{Overview}

Table 1 gives an overview of the samples, the sample sizes and the respective MTA thermal transitions identified in this study. In addition, the sample preparation method, supplier and solid state form as measured by XRPD are shown. The thermal transitions are compared to measurements with DSC, DMA, TGA and references from literature. All thermal events detected with conventional techniques were in good agreement with literature. MTA standard deviations (SD) originate from the direct triplicate measurements. MTA thermograms not shown in the main part, as well as all DSC, DMA, TGA and XRPD measurements are provided in the supporting information. The specific results are discussed in the following sections respectively. The sample mass is approximated by using equation 2 (a short derivation of the equation is provided in the supporting information), where $f_{o}$ is the initial resonance frequency of the uncoated string, $f_{\text {res }}$ the resonance frequency of the string covered with sample and $\mathrm{m}_{\mathrm{o}}$ the mass of the silicon nitride string:

$$
m_{\text {sample }}=\frac{\pi m_{0}\left(f_{0}^{2}-f_{\text {res }}^{2}\right)}{(\pi+2) f_{\text {res }}^{2}}
$$

MTA thermograms were recorded by first measuring $f_{r}$ of a blank uncoated string (reference) over the applied temperature range. Then the same string was covered with sample and measured again. Since the measurement laser is able to jump between different strings clamped on the same microchip in less than $0.2 \mathrm{~s}$, three strings, each with different amounts of sample, are measured simultaneously during each of the aforementioned runs. After completion, $f_{r}$ and $Q$ of the strings are extracted from the spectra (MTA-F and MTA-Q).

\section{Small Molecules}

Figure $2 \mathrm{a}$ shows the relative frequency change of a single string before and after depositing amorphous cimetidine. Additionally, the difference between reference and sample is shown. Reported values in Table 1 , as well as displayed MTA-F signals from Figure 3 onwards are from the respective difference between reference and sample (differential). Absolute values are taken as tangent intersects from the differential, as seen by the red and blue dotted lines (tangents) and the green circles (tangent intersects) in the figure. Except for a short thermal lag in the beginning, $f_{r}$ of the reference changes linearly $\left(R_{2}>99.6 \%\right.$ for all references made in this study): the silicon frame expands faster than the $\mathrm{Si}_{\mathrm{x}} \mathrm{N}_{\mathrm{y}}$ string with increasing temperature as the thermal expansion coefficient of silicon is higher than that of $\mathrm{Si}_{\mathrm{x}} \mathrm{N}_{\mathrm{y}}$, thus increasing the string's tensile stress. In contrast, the sample response shows several changes in slope that correspond to different thermal events in the sample. The reader is referred to Bose et al. ${ }^{8}$ for a theoretical explanation of the frequency changes for sample and reference. Additionally, the authors have supplied a short video in the supporting information that visually explains the measuring principle and observed signal responses.

The first major slope change in the MTA-F domain of amorphous cimetidine is recorded at $60^{\circ} \mathrm{C}$ and corresponds to the material's $\mathrm{T}_{\mathrm{g}}$. As can be seen in Figure $2 \mathrm{~b}-\mathrm{a}$ comparison between conventional DSC and MTA including the $\mathrm{Q}$ - the transition happens at higher temperatures than recorded by DSC, an observation consistently made in this study including for the $\mathrm{T}_{\mathrm{g}}$ of polymers. This can be attributed to two main reasons: instant frequency responses allow MTA thermograms to be recorded at 30 to $40^{\circ} \mathrm{C} / \mathrm{min}$, therefore exceeding standard DSC heating rates by a factor of three to four. A $\mathrm{T}_{\mathrm{g}}$ shift towards higher temperatures with higher applied heating or cooling rate is a well-documented phenomenon in the amorphous community. $^{30-31}$ Furthermore, a variety of physicochemical attributes change during the kinetic $\mathrm{T}_{\mathrm{g}}$. Depending on the measurement, absolute $\mathrm{T}_{\mathrm{g}}$ values can differ significantly, as for example seen by constantly higher values recorded by DMA than DSC for the same materials. $^{21,32}$ This variation in signal response is also underlined by the fact that a small deviation from the reference slope for MTA-F can already be noticed at values closer to the DSC midpoint $\mathrm{T}_{\mathrm{g}}$ values. This deviation is more pronounced in polymer samples and further discussed in the respective section below.

After the $\mathrm{T}_{\mathrm{g}}$, broad signal changes are seen in the region up to $139^{\circ} \mathrm{C}$ with slope change onsets of $85^{\circ} \mathrm{C}$ and $110^{\circ} \mathrm{C}$. This is identified as the crystallization region. Following DSC practice, where the kinetic crystallization is also seen over a wide temperature range but the crystallization temperature $\left(\mathrm{T}_{\mathrm{c}}\right)$ is often taken at the exotherm's maxi- 
Table 1. Overview of the samples used in the study and the respective thermal events detected

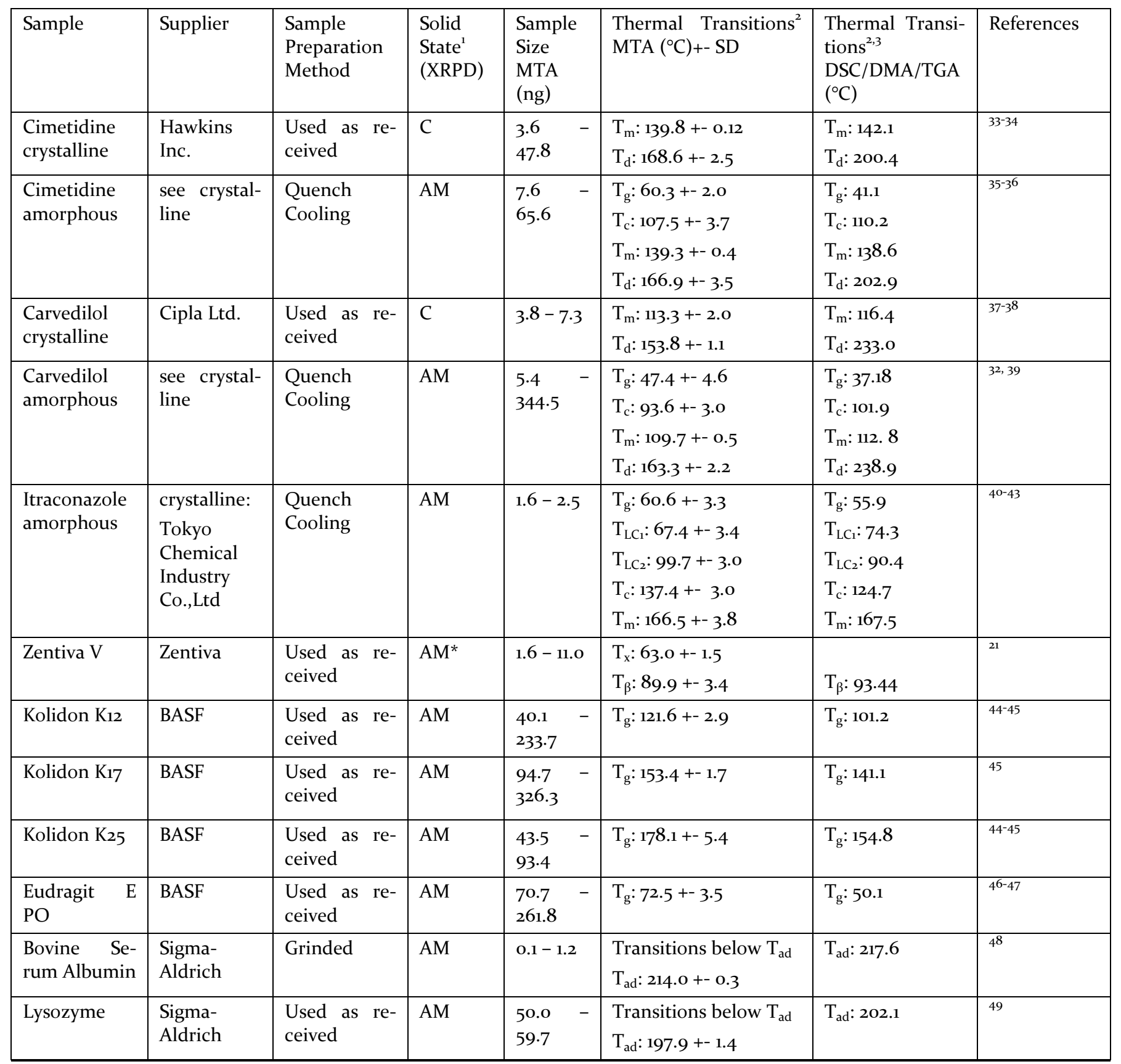

${ }^{1} \mathrm{AM}$ : amorphous, $\mathrm{C}$ : crystalline, ${ }^{2} \mathrm{~T}_{\mathrm{g}}$ : glass transition, $\mathrm{T}_{\mathrm{m}}$ : melting point, $\mathrm{T}_{\mathrm{c}}$ : crystallization point, $\mathrm{T}_{\mathrm{d}}$ : decomposition onset, $\mathrm{T}_{\beta}$ : beta relaxation, $\mathrm{T}_{\mathrm{x}}$ : unknown, $\mathrm{T}_{\mathrm{ad}}$ : apparent denaturation temperature, ${ }^{3} \mathrm{~T}_{\mathrm{g}}, \mathrm{T}_{\mathrm{m}}, \mathrm{T}_{\mathrm{c}}$ and $\mathrm{T}_{\mathrm{ad}}$ were measured with DSC, $\mathrm{T}_{\mathrm{d}}$ with TGA and $\mathrm{T}_{\beta}$ with DMA, *XRPD measurement not disclosed

mum, $T_{c}$ of the MTA thermogram is also taken at the $f_{r}$ minimum at $110^{\circ} \mathrm{C}$. While the region from 85 to $110^{\circ} \mathrm{C}$ exhibits a normal baseline, there are several distinct bumps noticeable after $110^{\circ} \mathrm{C}$. The authors attribute this to crystals forming from single particles: the energy released upon forming a crystal temporarily heats up the string. As the local change in temperature of the string is inversely correlated to $\mathrm{f}_{\mathrm{r}},{ }^{50}$ small temporary drops in $\mathrm{f}_{\mathrm{r}}$ occur in correlation with short exothermal events. Added in the supporting information is a microscopic picture series taken during the measurement which visually supports the for- mation of crystals from single particles. In addition, an initial quantification effort, that underlines the crystal formation, shown as the described frequency bumps, from very low amounts of sample ( 550 to $1870 \mathrm{pg}$ ) is given in the supporting information. The calculation is based on the geometric and material properties of the strings used, as well as the heat of fusion of the sample, as experimentally determined by DSC.

Following crystallization, a steep signal change is seen at $139^{\circ} \mathrm{C}$. This is the material's melting point. Note that, while for kinetic events (such as the $\mathrm{T}_{\mathrm{g}}$ ) differences in 

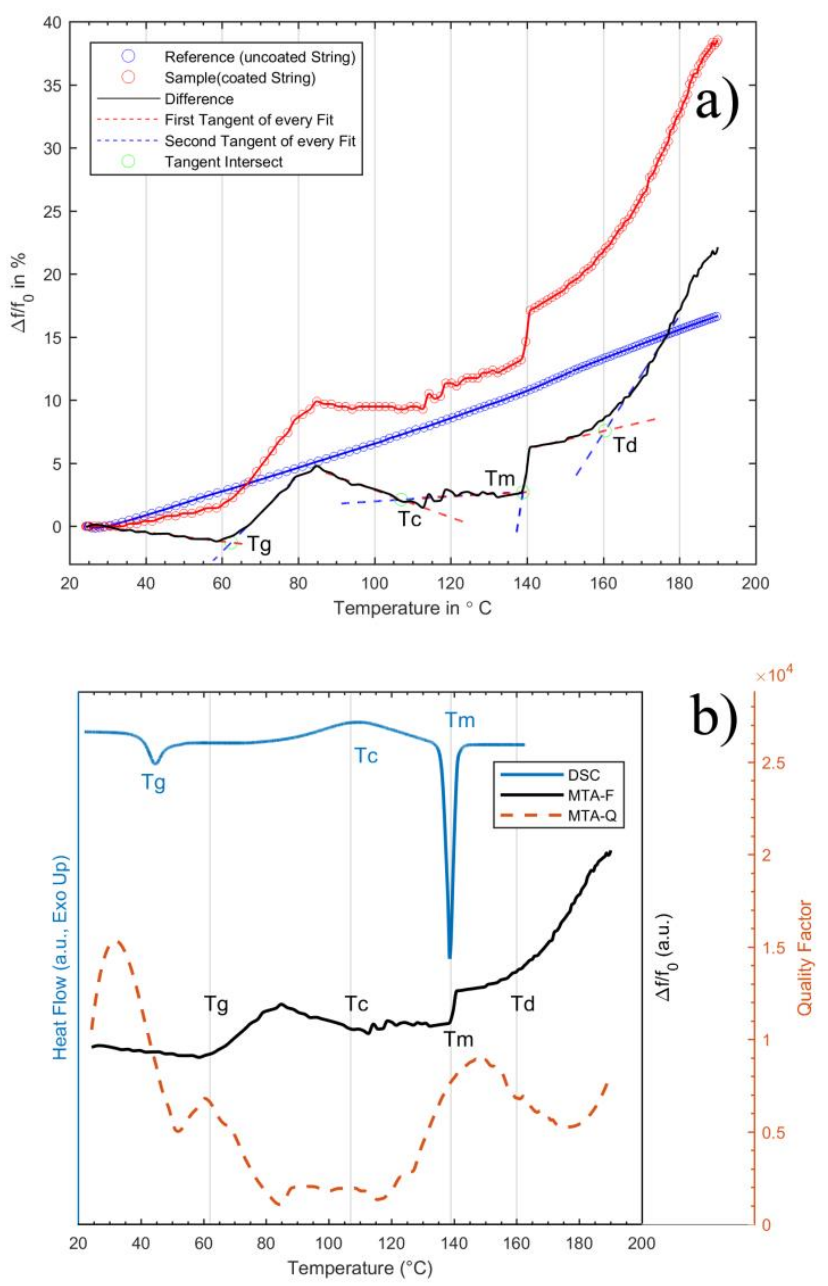
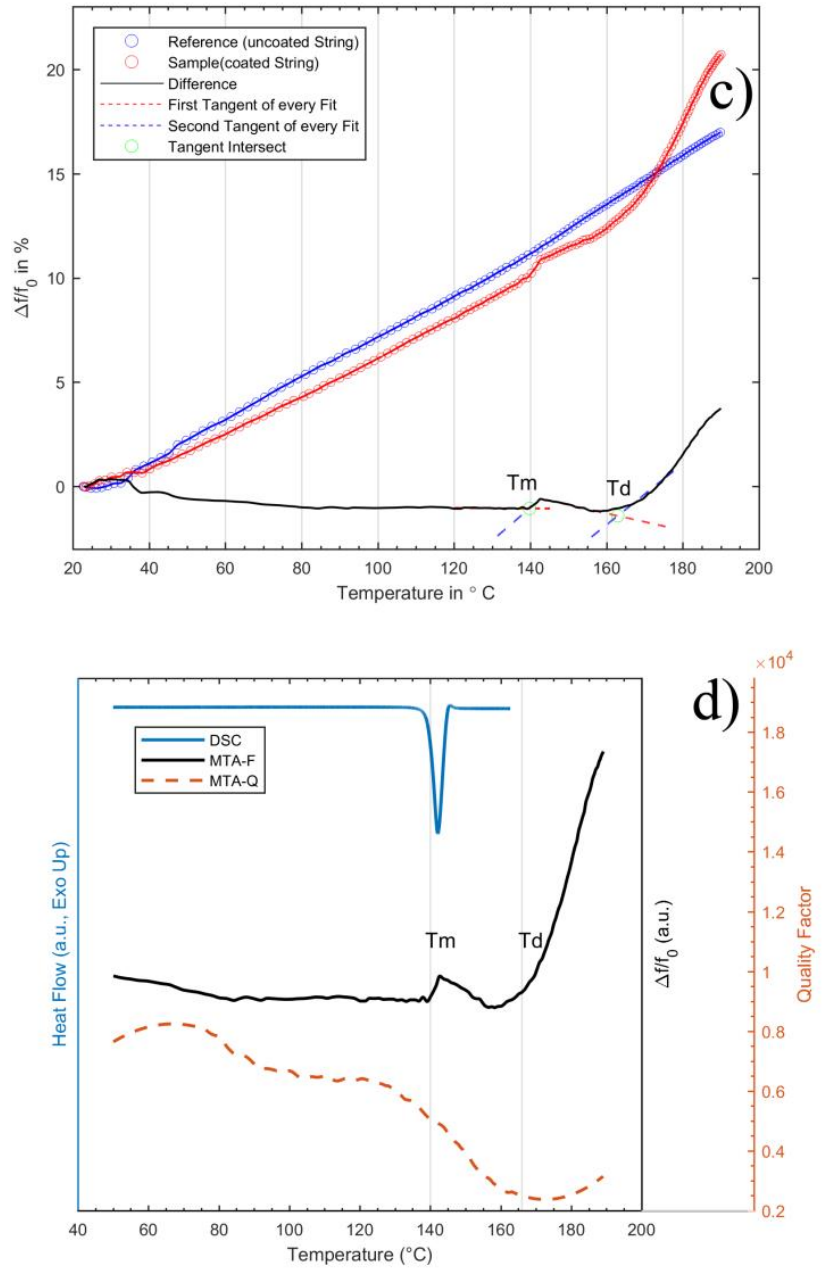

Figure 2. MTA thermograms of a string coated with amorphous (a) and crystalline (c) cimetidine and the corresponding references (uncoated string). Comparison between MTA including the Q factor domain and DSC for amorphous (b) and crystalline cimetidine (d). Vertical lines in b) and d) mark the thermal events detected by MTA-F.

absolute values are naturally present, the thermodynamic melting event is recorded at values in very good agreement with conventional techniques across all samples. At $160^{\circ} \mathrm{C}, \mathrm{f}_{\mathrm{r}}$ steeply rises due to material decomposition. During decomposition, material gases off the string, lowering the mass on the string sensor and thus increasing $\mathrm{f}_{\mathrm{r}}$. Decomposition is discussed in more detail below. Figure $2 \mathrm{~b}$ also introduces the $\mathrm{Q}$ measurements. The $\mathrm{Q}$ of a resonator is a measure for the rate of energy dissipation and is directly related to the viscoelastic material damping..$^{51}$ The damping is frequency dependent and therefore enables a more dynamical measure of the material. During the glass transition, $\mathrm{Q}$ drops due to higher internal friction in the material until it reaches a minimum. A noticeable lag in temperature between this minimum and the onset of frequency change in the MTA-F domain is seen. This lag was previously attributed to the difference of measuring static and dynamic portions of the $\mathrm{T}_{\mathrm{g}}$ (in polymer samples). ${ }^{8} \mathrm{As}$ soon as crystals are forming and the material becomes more rigid, $\mathrm{Q}$ rises, up to the crystals' melting, which causes another drop in $\mathrm{Q}$. The final rise in $\mathrm{Q}$ is due to the sample gassing off the string.

Except for an initial rise in $\mathrm{Q}$ due to damping dilution, ${ }^{51}$ the reference $\mathrm{Q}$ did not show any major signal changes during the temperature ramp. The reader is referred to the supporting information for a comparison between reference and sample $Q$ of this measurement.

Figure $2 \mathrm{c}$ and $\mathrm{d}$ represent measurements of crystalline cimetidine. As expected, only two major changes in the MTA-F and MTA-Q domain are seen for melting and decomposition.

A comparison of DSC and MTA-F for amorphous itraconazole (aITC) is shown in Figure 3.

As previously reported, upon heating, aITC forms two liquid crystalline mesophase ${ }^{40-43}$ : a smectic A and a nematic phase, seen by DSC endotherms at approx. $74^{\circ} \mathrm{C}$ and $90^{\circ} \mathrm{C}$, respectively.

Additionally to melting, crystallization and the $T_{g}$, the MTA-F measurement shows two major signals corresponding to the liquid crystalline mesophases. 


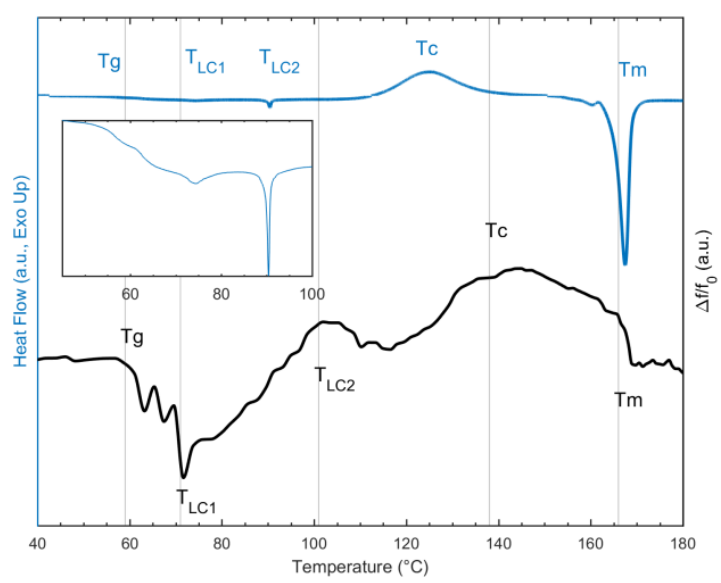

Figure 3. Comparison between MTA-F and DSC for amorphous itraconazole. The inset shows a zoomed in section of the DSC measurement between 50 and $100^{\circ} \mathrm{c}$. Vertical lines mark the thermal events detected by MTA-F.

Measured with the sensitive microstings, these signals are many magnitudes stronger compared to DSC. Leading up to the first liquid crystalline state, distinct baseline bumps are noticeable. As mentioned above, these can be signs of crystals forming as well as possible overlapping of the $T_{g}$ and mesophase formation. The MTA-F and Q response of the amorphous compound Zentiva V is compared to DMA in Figure 4. It was recently reported, that this compound shows a beta relaxation at roughly $90^{\circ} \mathrm{C}$ as measured with DMA. ${ }^{21}$

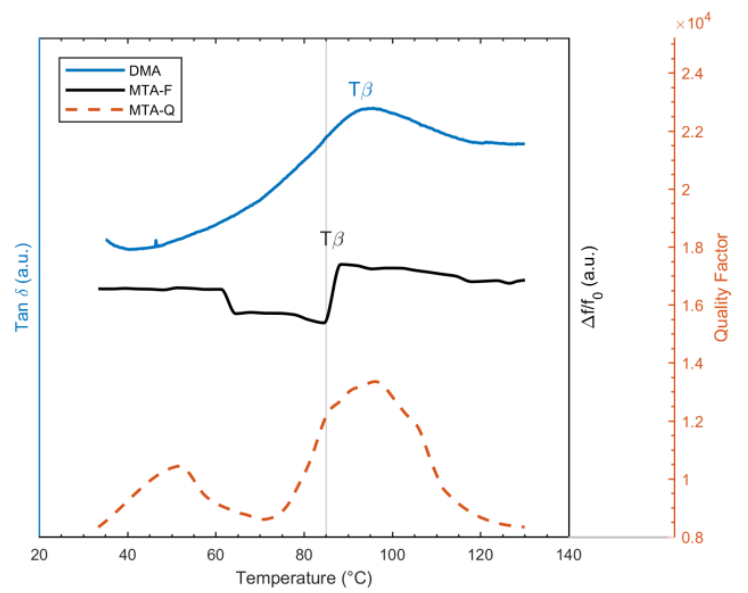

Figure 4. Comparison between MTA-F/Q and DMA of Zentiva $\mathrm{V}$. The vertical line marks the beta relaxation as identified by MTA-F.

The MTA-F domain shows two signals: a major signal at $86^{\circ} \mathrm{C}$, representing the beta relaxation and a smaller signal at $60^{\circ} \mathrm{C}$. Whether the smaller signal indicates another sub $\mathrm{T}_{\mathrm{g}}$ relaxation or is linked to the beta relaxation needs further investigation. Interestingly, the lag in thermal response between MTA-Q and F domain is considerably smaller than for the above mentioned $\mathrm{T}_{\mathrm{g}}$.

It has recently been described, that the beta relaxation can be measured by different techniques but is more lim- ited in temperature range, and this has been included in a fundamental theory by Ruggiero et al. ${ }^{24}$ Furthermore, the MTA-Q signal response is in very good agreement with the DMA measurement. This is expected as both measuring techniques are probing the dynamic properties of the material.

Figure 5 shows the decomposition profile of amorphous carvedilol deposited on three strings, including the respective references. The yellow, orange and blue lines represent an individual string of the direct triplicate measurement.

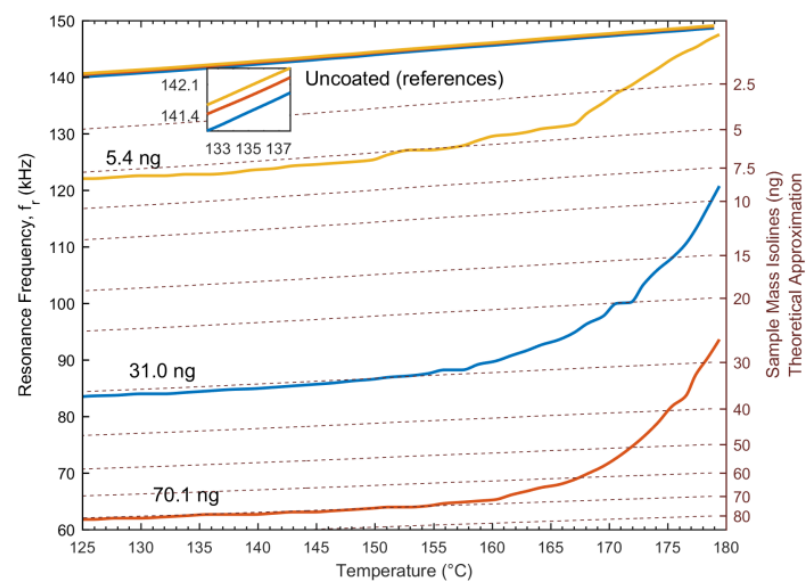

Figure 5. Decomposition profile of amorphous carvedilol including the reference measurements. Each of the colored lines represents an individually coated string. Labels above the sample lines show the sample mass before decomposition. The inset shows a zoomed in section of the references.

As can be seen, all references exhibit the same change in $\mathrm{f}_{\mathrm{r}}$ across the temperature range and only very small deviations, caused by the limits of uniformity in microchip production, are seen from the initial $\mathrm{f}_{\mathrm{r}}$. Consequently, a strong argument can be made, that it is only necessary to perform a single reference measurement for a given microchip geometry.

Similar to a TGA measurement, the theoretical sample size approximation allows for an easy tracking of the loss in sample mass. As mentioned above, $f_{r}$ rises due to the loss of sample mass and diverges to the reference value at the given temperature. Compared to TGA (see Table 1), sample decomposition starts at considerably lower temperatures. This is expected due to the lower initial sample mass, higher surface to volume ratio and especially due to the lower overall pressure in high vacuum.

\section{Polymers}

The $\mathrm{T}_{\mathrm{g}}$ measured by MTA-F, as well as DSC, of three PVP (Kolidon K12,K17 and K25) samples with increasing chain length is given in Figure 6.

As expected, and in agreement with literature, the $\mathrm{T}_{\mathrm{g}}$ values increase with increasing chain length, whereas the effect of increasing $T_{g}$ values diminishes for longer chain lengths. ${ }^{4-45},{ }^{52}$ It is noticeable, that for the MTA measure- 
ment there is one main change in the relative resonance frequency $\left(\mathrm{T}_{\mathrm{g}_{2}}\right)$ as well as another smaller change at lower temperatures $\left(\mathrm{T}_{\mathrm{g}_{1}}\right)$.

While $\mathrm{T}_{\mathrm{g}_{1}}$ is in good agreement with the absolute midpoint DSC values, $\mathrm{T}_{\mathrm{g}_{2}}$ is prominent after the DSC step change in heat capacity.

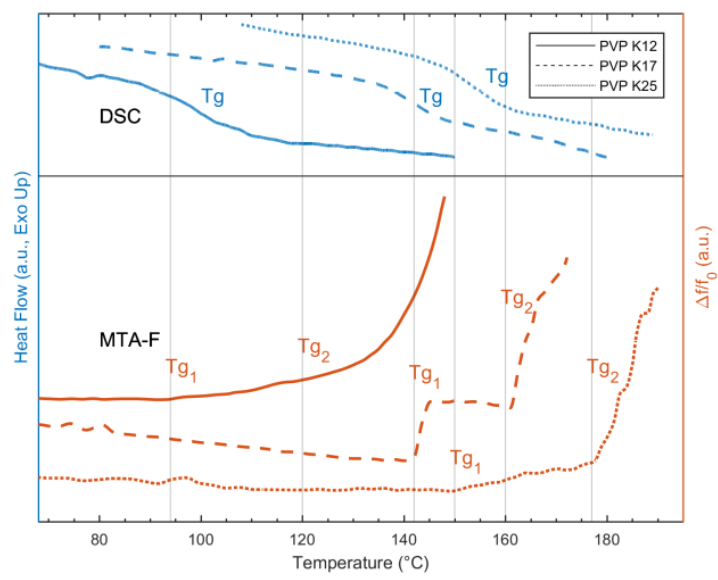

Figure 6. MTA-F thermograms of PVP K12, K17 and K25 compared to DSC. Vertical lines mark the thermal events detected by MTA-F.

This implies, that the string resonators are able to pick up a physical sample change during $\mathrm{T}_{\mathrm{g}}$, which is not linked to a change in heat capacity and is more sensitive to our measurement technique. To have a more detailed view on the $\mathrm{T}_{\mathrm{g}}$ by MTA and its comparability to conventional techniques, a specialized study is needed.

\section{Proteins}

Even though freeze-dried solid state protein samples are of special interest in research and industry due to their physical stability, thermal protein characterization in literature is often done in buffered aqueous solutions. ${ }^{53}$ One key reason for this literature gap is the lack of sensitivity in conventional techniques like DSC for the detection of thermal events in the solid state, such as the $\mathrm{T}_{\mathrm{g}}$. Most dry proteins behave as strong glasses with a spread-out $\mathrm{T}_{\mathrm{g}}$ and a very small change in heat capacity at the $\mathrm{T}_{\mathrm{g}} \cdot{ }^{28}$ Therefore, the $\mathrm{T}_{\mathrm{g}}$ in dry proteins is estimated by extrapolation of DSC data of excipient (e.g. disaccharides) and protein mixtures. Consistent in the literature is furthermore, that proteins in the solid state show an irreversible denaturation, in most cases well above $100^{\circ} \mathrm{C}$, which is assumed to only take place after the glass transition and is seen in the DSC as an endotherm. ${ }^{54}$ Its corresponding temperature is sometimes referred to as the apparent denaturation temperature. $^{49}$

A comparison of MTA-F (direct triplicate) and DSC data of lysozyme is given in Figure 7a. The DSC data shows, in agreement with literature, two main thermal events: the water endotherm at roughly $100^{\circ} \mathrm{C}$ and the apparent denaturation temperature at $202^{\circ} \mathrm{C} .{ }^{49}$ In contrast to the polymer and small molecule samples used in this study, the protein samples showed only partially consistent signal responses between the direct triplicate measurement as seen in Figure 7a. While all strings show a distinct slope change at $198^{\circ} \mathrm{C}$, indicating the apparent denaturation, many more signals are present below $180^{\circ} \mathrm{C}$, which are not reflected in the DSC measurement. All strings show the most pronounced frequency changes in the region of 125 to $152^{\circ} \mathrm{C}$. Furthermore many smaller signals are identified leading up to $110^{\circ} \mathrm{C}$. For BSA (Figure $7 \mathrm{~b}$ ), apart from the apparent denaturation temperature, a broad signal is present in the region of $153^{\circ} \mathrm{C}$ to $202^{\circ} \mathrm{C}$ for two out of three strings, as well as smaller signals at lower temperatures. In order to account for the possible water loss of MTA samples, lysozyme samples were also pretreated under the same vacuum exposure conditions as MTA samples and measured with DSC: DSC pans with lysozyme sample were placed in the vacuum chamber and exposed to premeasurement MTA conditions.

a)

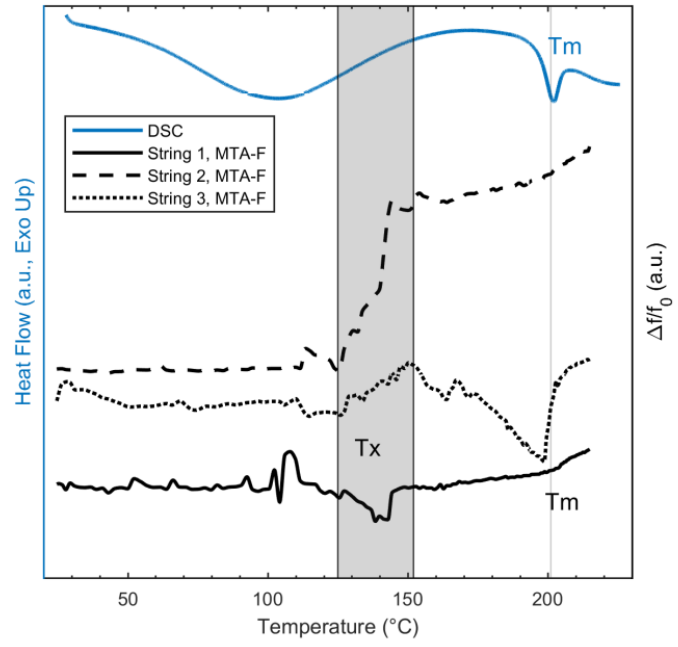

b)

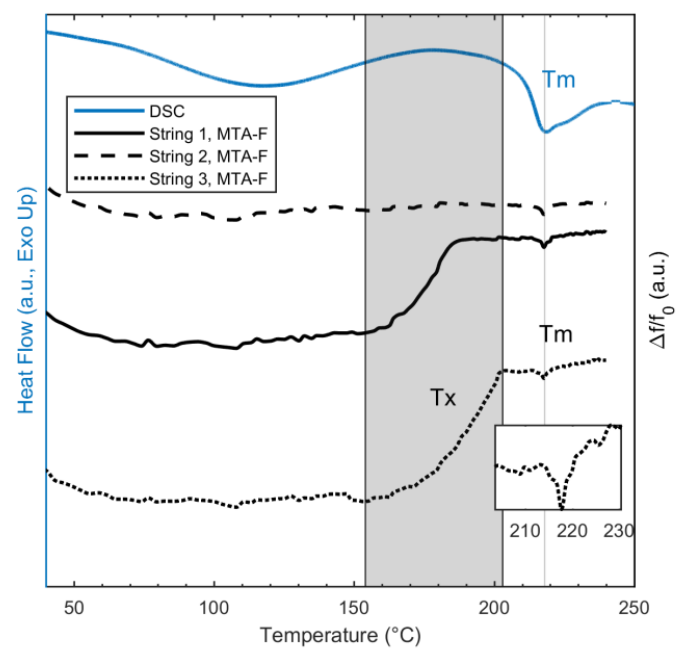

Figure 7. MTA-F thermograms of three different strings of a direct triplicate compared to DSC for lysozyme (a) and BSA (b). The vertical line marks the apparent denaturation temperature (Tm) and the grey area marks a strong unknown signal detected by MTA-F. The inset in (b) shows a zoomed in section of the third string from 210 to $230{ }^{\circ} \mathrm{C}$. 
a)

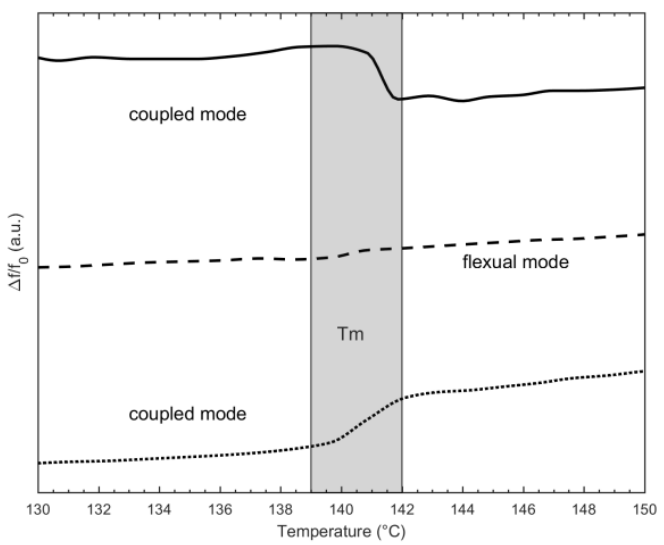

b)

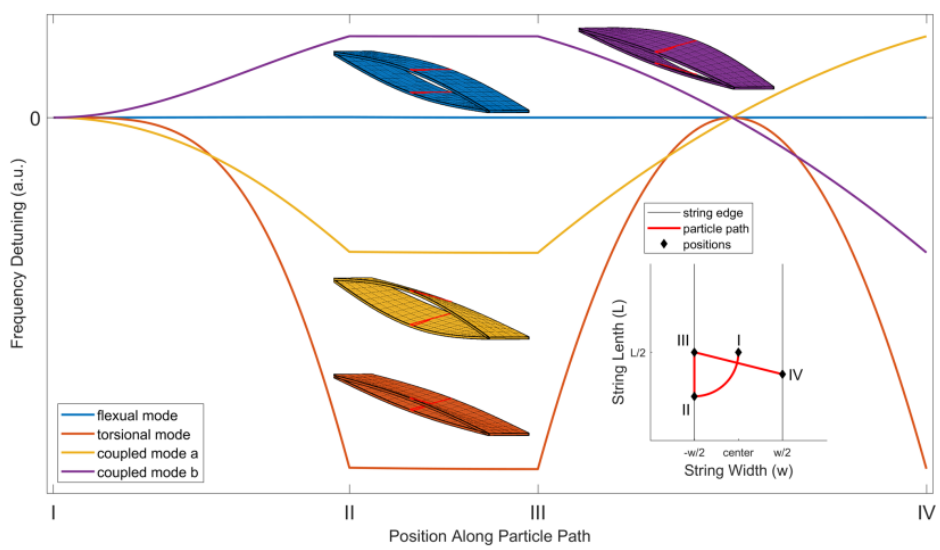

Figure 8. (a) Relative frequency response of three different modes tracked from a single string coated with amorphous cimetidine during melting. (b) Theoretical illustration of the frequency response to changes in effective mass of different modes. The changes in effective mass are caused by a particle which is moving along the surface. The particle path is shown in the inset of the figure.

After withdrawing the vacuum, the DSC pan was immediately closed and measured within three minutes. While the water content was significantly reduced (see supporting information for the DSC measurement with and without vacuum pretreatment), there is still a considerable amount of water left in the samples. Smaller signal changes in MTA-F, happening at lower temperatures for both protein samples might therefore be attributed to the loss of residual water at different sites of the protein.

Other possibilities for the overall signal responses might include intra- or intermolecular motions, folding phenomena or changes in quaternary structure. A very small pre- $T_{g}$ DSC endotherm has for example been linked to protein internal dynamics for BSA. ${ }^{48}$ Furthermore, a recent study from Lopes-Rodrigues et al. ${ }^{55}$ shows that BSA and lysozyme undergo a thermal unfolding with a drastic change in secondary structure at temperatures already below $100^{\circ} \mathrm{C}$ as measured with conventional techniques and a microcantilever based approach. The two broader and more intense slope changes of the samples (starting at $125^{\circ} \mathrm{C}$ for lysozyme and $153^{\circ} \mathrm{C}$ for BSA respectively) indicate a stronger cooperative motion. The signal dependence on sample size and sample distribution on the strings can explain signal variations seen in MTA-F. Different mode responses (see next section) might moreover explain the signal vanishing of one of the BSA sample strings and the opposing signal slope change of one of the lysozyme sample strings.

The $\mathrm{T}_{\mathrm{g}}$ of BSA has been approximated with the above mentioned extrapolation method in (48). The value of $134^{\circ} \mathrm{C}$, obtained from two sugar mixtures, is in good agreement with the onset of the broad signal in MTA-F at $153^{\circ} \mathrm{C}$. Note, that the main onset slope change for the $T_{\mathrm{g}}$ in MTA-F is at slightly higher temperatures than the corresponding DSC $\mathrm{T}_{\mathrm{g}}$. The average difference between DSC and MTA-F for absolute glass transition values of all small molecule and polymer samples in this study is $+15.9^{\circ} \mathrm{C}$. If this is coincidental or if the broad signal is indeed the $\mathrm{T}_{\mathrm{g}}$, requires further investigation. In order to clarify and compare these interesting, yet unseen signal responses, an in depth study with varying sample water content, protein samples with different thermal folding behaviour and comparison to solid state NMR and molecular level techniques such as vibrational spectroscopy should be conducted.

\section{Signal Resposes of Different Modes}

In some experiments, it was observed that the resonance frequency response to certain thermal events can be different in magnitude and shape within a single measurement triplicate.

This can be explained by the fact that mechanical resonators can resonate in many different shapes and the random nature of sample deposition can make one kind of resonance mode more pronounced than another.

Figure 8a shows the frequency response of three individual resonance modes of a single string covered with amorphous cimetidine during melting. Note, that these are not just the different harmonic flexural resonance modes $(n=1,2,3, \ldots)$ described by equation (1). While two modes display large frequency changes in opposite directions, one mode only shows a modest increase. This can, amongst other factors, be attributed to changes in effective mass of the resonator which are notably present during thermal events that include liquefaction like melting or $\mathrm{T}_{\mathrm{g}}$.

Figure $8 \mathrm{~b}$ illustrates the theoretical influence of the movement of an added mass particle (the particle path is shown in the inset) on different resonance modes. While the mass of the system stays constant during particle movement, the effective mass (taking the shape of the vibration into account) changes. The figure shows that very small movements of mass on the sensor surface can have very different effects on different resonance modes. This is because the local mass responsivity scales with the square of the local vibrational amplitude of a given resonance mode. 
Getting back to the example of melting cimetidine, the formation of droplets on the sensor leads to a minor redistribution of mass, which in turn can have huge effects on some resonance modes.

As these different frequency responses still have the same onset points for specific thermal events, the different modes can in future be used to boost the sensitivity for specific events. Moreover, different mode responses can help to distinguish thermal events such as melting and decomposition.

By using the build in vibrometer software, it is furthermore possible to visualize different resonance mode shapes. A short animation of different modes of a string covered with sample and an example of different frequency responses are supplied in the supporting video.

\section{CONCLUSIONS}

In this study we have shown that $\mathrm{Si}_{\mathrm{x}} \mathrm{N}_{\mathrm{y}}$ microstring sensors can successfully be utilized for fast thermomechanical characterization of a variety of samples. By establishing a simple sampling procedure and a post process data analysis procedure, our method reaches the level of convenience of conventional commercially available thermal analysis techniques with the possibility of recording instant instrumental triplicates. Moreover, the presented results with pico- to nanograms of sample demonstrate the high sensitivity of the method for the detection of thermal events in agreement with DSC and DMA measurements. Utilizing this level of sensitivity, we have detected yet unreported thermal events for protein samples, and were able to capture a detailed view on the glass transition, beta relaxation and crystallization of amorphous small molecule drugs. With further investigation, the reported level of sensitivity will help to create valuable insight in the still debated underlying physico-chemical fundamentals of these thermal transitions. Different resonance mode shapes, such as torsional modes of the string resonator can further increase the sensitivity of specific thermal events and will in future be exploited for an internal validation of the method. Further method development of MTA is of more practical nature, such as expanding the temperature range with the use of liquid nitrogen. Additionally, an optimization of the setup and microchip geometry can allow for measurement pressures closer to ambient conditions and capacitative or optical lever read out can remove the vibrometer as a bulky and expensive read out instrument. Altogether, our study highlights the capability of resonant string MEMS sensors for further development and application of MTA in instrumental chemical analysis to shed light on yet unresolved thermal responses of small and large molecule samples.

\section{ASSOCIATED CONTENT}

Supporting Information. Equations for the $Q$ fitting and the sample mass approximation. Data filter for the $Q$ signal used in this study. DSC, DMA, TGA and XRPD (except Zentiva $\mathrm{V}$ ) measurements. MTA thermograms not shown in the main part of the manuscript. $Q$ comparison between sample and reference (amorphous cimetidine as example). Comparison of lysozyme DSC measurements with and without vacuum pretreatment. Video about the measuring principle and different resonance modes as web enhanced object.

\section{AUTHOR INFORMATION}

\section{Corresponding Author}

*thomas.rades@sund.ku.dk

\section{ACKNOWLEDGMENT}

Zentiva V (real name concealed) is an amorphous drug at room temperature in development by Zentiva k.s. Prague, Czech Republic. The authors would like to thank Zentiva for supplying the sample. This research has received funding by the Danish National Research Foundation (DNRF122) and Villum Fonden (Grant No. 9301). The authors would like to thank Eric Ofosu Kissi at the Department of Pharmacy, University of Copenhagen for the DMA measurement.

\section{REFERENCES}

1. Mehrnaz, M.; Raafat, R. M.; Amir, K., Novel MEMS filters for on-chip transceiver architecture, modeling and experiments. $J$. Micromech. Microeng. 2006, 16 (2), 407-418.

2. Kurek, M.; Carnoy, M.; Larsen, P. E.; Nielsen, L. H.; Hansen, O.; Rades, T.; Schmid, S.; Boisen, A., Nanomechanical Infrared Spectroscopy with Vibrating Filters for Pharmaceutical Analysis. Angew. Chem. Int. Ed. Engl. 2017, 56 (14), 3901-3905.

3. Zielinski, A. T.; Gallimore, P. J.; Griffiths, P. T.; Jones, R. L.; Seshia, A. A.; Kalberer, M., Measuring Aerosol Phase Changes and Hygroscopicity with a Microresonator Mass Sensor. Anal. Chem. 2018, Just Accepted Manuscript.

4. Anja, B.; Søren, D.; Stephan Sylvest, K.; Silvan, S.; Maria, T., Cantilever-like micromechanical sensors. Rep. Prog. Phys. 2011, 74 (3), 036101.

5. Stegner, J.; Gropp, S.; Podoskin, D.; Stehr, U.; Hoffmann, M.; Hein, M., An Analytical Temperature-Dependent Design Model for Contour-Mode MEMS Resonators and Oscillators Verified by Measurements. Sensors 2018, 18 (7), 2159.

6. Jung, N.; Seo, H.; Lee, D.; Ryu, C. Y.; Jeon, S., Nanomechanical Thermal Analysis of the Glass Transition of Polystyrene Using Silicon Cantilevers. Macromolecules 2oo8, 41 (19), $6873-6875$.

$7 . \quad J u n g$, N.; Jeon, S., Nanomechanical Thermal Analysis with Silicon Cantilevers of the Mechanical Properties of Poly(vinyl acetate) near the Glass Transition Temperature. Macromolecules 2008, 41 (24), 9819-9822.

8. Bose, S.; Schmid, S.; Larsen, T.; Keller, S. S.; SommerLarsen, P.; Boisen, A.; Almdal, K., Micromechanical String Resonators: Analytical Tool for Thermal Characterization of Polymers. ACS Macro Lett. 2014, 3 (1), 55-58.

9. Bose, S.; Schmid, S.; Larsen, T.; Sylvest Keller, S.; Boisen, A.; Almdal, K., Micromechanical fast quasi-static detection of $\alpha$ and $\beta$ relaxations with nanograms of polymer. J. Polym. Sci., Part B: Polym. Phys. 2015, 53 (15), 1035-1039.

10. Manzoor Bukhari, S. A.; Khan, M. F.; Goswami, A.; McGee, R.; Thundat, T., Thermomechanical analysis of picograms of polymers using a suspended microchannel cantilever. RSC Adv. 2017, 7 (14), 8415-8420.

11. Yim, C.; Yun, M.; Kim, S.; Jung, N.; Lim, S.-H.; Lee, M.; Rhee, S.-W.; Thundat, T.; Jeon, S., Nanomechanical Thermal Analysis of Indium Films Using Silicon Microcantilevers. Jpn. J. Appl. Phys. 2012, 51, o8KBo7.

12. Yun, M.; Jung, N.; Yim, C.; Jeon, S., Nanomechanical thermal analysis of the effects of physical aging on glass transitions 
in PS/PMMA blend and PS-PMMA diblock copolymers. Polymer 2011, 52 (18), 4136-4140.

13. Soccio, M.; Luongo, G.; Esteves, C.; Salvador-Matar, A.; Ahumada, O.; Rueda, D. R.; García-Gutiérrez, M. C.; Lotti, N.; Munari, A.; Ezquerra, T. A., Thermomechanical response of a semicrystalline polymer in the vicinity of the melting by using microcantilever technology. Appl. Phys. Lett. 2014, 104 (25), 251904.

14. Ahumada, O.; Pérez-Madrigal, M. M.; Ramirez, J.; Curcó, D.; Esteves, C.; Salvador-Matar, A.; Luongo, G.; Armelin, E.; Puiggalí, J.; Alemán, C., Sensitive thermal transitions of nanoscale polymer samples using the bimetallic effect: Application to ultra-thin polythiophene. Rev. Sci. Instrum. 2013, 84 (5), 053904.

15. Bose, S.; Keller, S. S.; Alstrøm, T. S.; Boisen, A.; Almdal, K., Process Optimization of Ultrasonic Spray Coating of Polymer Films. Langmuir 2013, 29 (23), 6911-6919.

16. Pataky, K.; Auzelyte, V.; Brugger, J., Inkjet Printing for MEMS. In Inkjet-Based Micromanufacturing, Korvink, J. G.; Smith, P. J.; Shin, D.-Y., Eds. Wiley-VCH Verlag \& Co. KgaA: Weinheim, Germany, 2012; pp 331-346.

17. de Jongh, P. E.; Eggenhuisen, T. M., Melt infiltration: an emerging technique for the preparation of novel functional nanostructured materials. Adv. Mater. 2o13, 25 (46), 6672-9o.

18. Schmid, S.; Kurek, M.; Adolphsen, J. Q.; Boisen, A., Realtime single airborne nanoparticle detection with nanomechanical resonant filter-fiber. Scientific Reports 2013, 3, 1288.

19. Schmid, S.; Villanueva, L. G.; Roukes, M. L., Resonance Frequency. In Fundamentals of Nanomechanical Resonators, Springer International Publishing: Switzerland, 2016; pp 1-56.

2o. Knopp, M. M.; Löbmann, K.; Elder, D. P.; Rades, T.; Holm, R., Recent advances and potential applications of modulated differential scanning calorimetry (mDSC) in drug development. Eur. J. Pharm. Sci. 2016, 87, 164-173.

21. Kissi, E. O.; Grohganz, H.; Löbmann, K.; Ruggiero, M. T.; Zeitler, J. A.; Rades, T., Glass-Transition Temperature of the $\beta$ Relaxation as the Major Predictive Parameter for Recrystallization of Neat Amorphous Drugs. J. Phys. Chem. B 2018, 122 (10), 2803-2808.

22. Yu, L., Amorphous pharmaceutical solids: preparation, characterization and stabilization. Adv. Drug Delivery Rev. 20o1, 48 (1), 27-42.

23. Wyttenbach, N.; Kuentz, M., Glass-forming ability of compounds in marketed amorphous drug products. Eur. J. Pharm. Biopharm. 2017, 112, 204-208.

24. Ruggiero, M. T.; Krynski, M.; Kissi, E. O.; Sibik, J.; Markl, D.; Tan, N. Y.; Arslanov, D.; van der Zande, W.; Redlich, B.; Korter, T. M.; Grohganz, H.; Lobmann, K.; Rades, T.; Elliott, S. R.; Zeitler, J. A., The significance of the amorphous potential energy landscape for dictating glassy dynamics and driving solid-state crystallisation. PCCP 2017, 19 (44), 30039-30047.

25. Pardo, L. C.; Lunkenheimer, P.; Loidl, A., Dielectric spectroscopy in benzophenone: The beta relaxation and its relation to the mode-coupling Cole-Cole peak. Physical Review E 2007, 76 (3), 030502 .

26. Sibik, J.; Löbmann, K.; Rades, T.; Zeitler, J. A., Predicting Crystallization of Amorphous Drugs with Terahertz Spectroscopy. Mol. Pharmaceutics 2015, 12 (8), 3062-3068.

27. Carraher, C., Polymer Structure (Morphology). In Polymer Chemistry, LAGOWSKI, J. J., Ed. Marcel Dekker, Inc.: New York, 2003; Vol. 6.

28. Pikal, M. J.; Rigsbee, D. R.; Roy, M. L., Solid state chemistry of proteins: I. glass transition behavior in freeze dried disaccharide formulations of human growth hormone (hGH). $J$. Pharm. Sci. 2007, 96 (10), 2765-2776.

29. Chang, B.; Y Patro, S., Freeze-drying Process Development for Protein Pharmaceuticals. In Lyophilization of Biopharmaceuticals, Costantino, H. R.; Pikal, M. J., Eds. American Association of Pharmaceutical Scientists: Arlington, VA, 2004; pp 113-138.

3o. Karmwar, P.; Boetker, J. P.; Graeser, K. A.; Strachan, C. J.; Rantanen, J.; Rades, T., Investigations on the effect of different cooling rates on the stability of amorphous indomethacin. Eur. J. Pharm. Sci. 2011, 44 (3), 341-350.
31. Brüning, R.; Samwer, K., Glass transition on long time scales. Physical Review B 1992, 46 (18), 11318-11322.

32. Blaabjerg, L. I.; Lindenberg, E.; Rades, T.; Grohganz, H.; Löbmann, K., Influence of preparation pathway on the glass forming ability. Int. J. Pharm. 2017, 521 (1), 232-238.

33. Bauer-Brandl, A., Polymorphic transitions of cimetidine during manufacture of solid dosage forms. Int. J. Pharm. 1996, 140 (2), 195-206.

34. Shibata, M.; Kokubo, H.; Morimoto, K.; Morisaka, K.; Ishida, T.; Inoue, M., X-ray Structural Studies and Physicochemical Properties of Cimetidine Polymorphism. J. Pharm. Sci. 1983, 72 (12), 1436-1442.

35. Wei, L. A.; Korbinian, L.; Holger, G.; Thomas, R.; Norman, C., Investigation of physical properties and stability of indomethacin-cimetidine and naproxen-cimetidine co-amorphous systems prepared by quench cooling, coprecipitation and ball milling. J. Pharm. Pharmacol. 2016, 68 (1), 36-45.

36. Allesø, M.; Chieng, N.; Rehder, S.; Rantanen, J.; Rades, T.; Aaltonen, J., Enhanced dissolution rate and synchronized release of drugs in binary systems through formulation: Amorphous naproxencimetidine mixtures prepared by mechanical activation. J. Controlled Release 2oo9, 136 (1), 45-53.

37. Hiendrawan, S.; Widjojokusumo, E.; Veriansyah, B.; Tjandrawinata, R. R., Pharmaceutical Salts of Carvedilol: Polymorphism and Physicochemical Properties. AAPS PharmSciTech 2017, 18 (4), 1417-1425.

38. Talvani, A.; Bahia, M. T.; de Sá-Barreto, L. C. L.; Lima, E. M.; da Cunha-Filho, M. S. S., Carvedilol: decomposition kinetics and compatibility with pharmaceutical excipients. J. Therm. Anal. Calorim. 2014, 115 (3), 2501-2506.

39. Genina, N.; Hadi, B.; Löbmann, K., Hot Melt Extrusion as Solvent-Free Technique for a Continuous Manufacturing of DrugLoaded Mesoporous Silica. J. Pharm. Sci. 2018, 107 (1), 149-155.

40. Tarnacka, M.; Adrjanowicz, K.; Kaminska, E.; Kaminski, K.; Grzybowska, K.; Kolodziejczyk, K.; Wlodarczyk, P.; Hawelek, L.; Garbacz, G.; Kocot, A.; Paluch, M., Molecular dynamics of itraconazole at ambient and high pressure. PCCP 2013, 15 (47), 20742-20752.

41. $\quad$ Six, K.; Verreck, G.; Peeters, J.; Augustijns, P.; Kinget, R.; Van den Mooter, G., Characterization of glassy itraconazole: a comparative study of its molecular mobility below $\mathrm{Tg}$ with that of structural analogues using MTDSC. Int. J. Pharm. 2001, 213 (1), 163173 .

42. Six, K.; Verreck, G.; Peeters, J.; Binnemans, K.; Berghmans, H.; Augustijns, P.; Kinget, R.; Van den Mooter, G., Investigation of thermal properties of glassy itraconazole: identification of a monotropic mesophase. Thermochim. Acta 20o1, 376 (2), 175-181.

43. Ramos, J. J. M.; Diogo, H. P., The slow relaxation dynamics in active pharmaceutical ingredients studied by DSC and TSDC: Voriconazole, miconazole and itraconazole. Int. J. Pharm. 2016, 501 (1), 39-48.

44. Knopp Matthias, M.; Olesen Niels, E.; Holm, P.; Langguth, P.; Holm, R.; Rades, T., Influence of Polymer Molecular Weight on Drug-Polymer Solubility: A Comparison between Experimentally Determined Solubility in PVP and Prediction Derived from Solubility in Monomer. J. Pharm. Sci. 2015, 104 (9), 2905-2912.

45. Doreth, M.; Löbmann, K.; Priemel, P.; Grohganz, H.; Taylor, R.; Holm, R.; Lopez de Diego, H.; Rades, T., Influence of PVP molecular weight on the microwave assisted in situ amorphization of indomethacin. Eur. J. Pharm. Biopharm. 2018, 122, 62-69.

46. Sathigari, S. K.; Radhakrishnan, V. K.; Davis, V. A.; Parsons, D. L.; Babu, R. J., Amorphous-state characterization of efavirenz-polymer hot-melt extrusion systems for dissolution enhancement. J. Pharm. Sci. 2012, 101 (9), 3456-3464.

47. Parikh, T.; Gupta, S. S.; Meena, A.; Serajuddin, A. T. M., Investigation of thermal and viscoelastic properties of polymers relevant to hot melt extrusion, III: polymethacrylates and polymethacrylic acid based polymers. J. Excipients Food Chem. 2014, (1), 56-64.

48. Mizuno, M.; Pikal, M. J., Is the pre-Tg DSC endotherm observed with solid state proteins associated with the protein 
internal dynamics? Investigation of bovine serum albumin by solid state hydrogen/deuterium exchange. Eur. J. Pharm. Biopharm. 2013, 85 (2), 170-176.

49. Elkordy, A. A.; Forbes, R. T.; Barry, B. W., Stability of crystallised and spray-dried lysozyme. Int. J. Pharm. 2004, 278 (2), 209-219.

50. Larsen, T.; Schmid, S.; Villanueva, L. G.; Boisen, A., Photothermal Analysis of Individual Nanoparticulate Samples Using Micromechanical Resonators. ACS Nano 2o13, 7 (7), 6188-6193.

51. Schmid, S.; Villanueva, L. G.; Roukes, M. L., Quality Factor. In Fundamentals of Nanomechanical Resonators, Springer International Publishing: Switzerland, 2016; pp 57-9o.

52. Buera, M. d. P.; Levi, G.; Karel, M., Glass transition in poly(vinylpyrrolidone): effect of molecular weight and diluents. Biotechnol. Progr. 1992, 8 (2), 144-148.

53. Chiu, M.; Prenner, E., Differential scanning calorimetry: An invaluable tool for a detailed thermodynamic characterization of macromolecules and their interactions. Journal of Pharmacy And Bioallied Sciences 2011, 3 (1), 39-59.

54. Pikal, M. J.; Rigsbee, D.; Akers, M. J., Solid state chemistry of proteins IV. what is the meaning of thermal denaturation in freeze dried proteins? J. Pharm. Sci. 2009, 98 (4), 1387-1399.

55. Lopes-Rodrigues, M.; Puiggalí-Jou, A.; Martí-Balleste, D.; del Valle, L. J.; Michaux, C.; Perpète, E. A.; Alemán, C., Thermomechanical Response of a Representative Porin for Biomimetics. ACS Omega 2018, 3 (7), 7856-7867. 
Insert Table of Contents artwork here

1

2

3

4

5

6

7

8

9

10

11

12

13

14

15

16

17

18

19

20

21

22

23

24

25

26

27

28

29

30

31

32

33

34

35

36

37

38

39

40

41

42

43

44

45

46

47

48

49

50

51

52

53

54

55

56

57

58

59

60

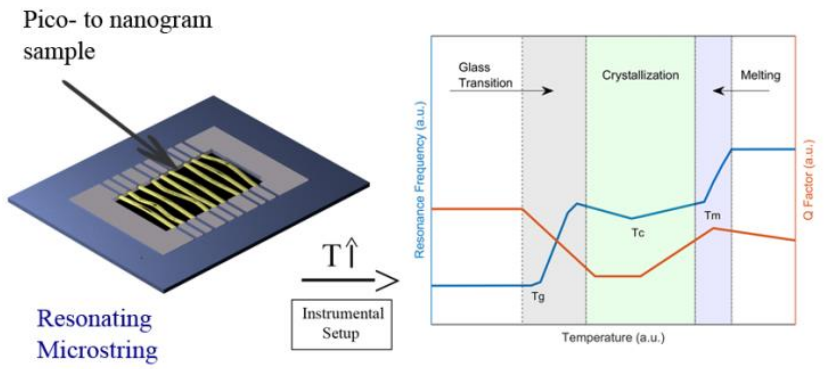

Sensor 